\title{
Non-invasive methods for the assessment of biomarkers and their correlation with radiographic maturity indicators - a scoping review
}

\author{
Veena GV and Tulika Tripathi ${ }^{*}$ (D)
}

\begin{abstract}
Background: Detection of skeletal maturity is vital in orthodontic treatment timing and planning. Traditional methods include hand-wrist radiography and cervical vertebral maturation index (CVMI). Though the radiographic methods are well established and routinely used to assess skeletal maturation, they carry the drawback of subjective perception and low reproducibility. With evolving concepts, skeletal maturation has been assessed quantitatively through biomarkers obtained from saliva, gingival crevicular fluid (GCF), and urine. The scoping review aims to explore the various biomarkers assessed through non-invasive methods and their correlation with radiographic skeletal maturity.
\end{abstract}

Methodology: The literature search was carried out on MEDLINE via Pubmed, Cochrane Library (Cochrane database of systematic reviews), Cochrane central register of controlled trials (CENTRAL), Google Scholar, Semantic Scholar, ScienceDirect, and Opengrey.eu for articles up to and including November 2020. Pertinent articles were selected based on inclusion and exclusion criteria. The results were tabulated based on the type of sample collected, the biomarker assessed, method of sample collection, and the radiographic method used.

Results: The literature search resulted in 12 relevant articles. Among all the studies, 10 studies showed that the concentration of biomarkers increases during the pubertal growth peak. On the contrary, 2 articles showed no significant difference between the levels of biomarkers and pubertal growth peak.

Conclusion: It can be concluded that the level of biomarkers increases during the pubertal growth spurt and can provide a quantitative way of assessing skeletal maturity.

Keywords: Saliva, Gingival crevicular fluid, Urine, Biomarker, Puberty, Maturity

\section{Introduction}

Assessment of maturation with particular regard to the onset of pubertal growth provides critical information about the likelihood of growth changes occurring in the craniofacial structures. This has a bearing on timing the orthodontic treatment by utilizing the growth potential, especially when dealing with skeletal disharmonies.

\footnotetext{
* Correspondence: drtulikatripathi@yahoo.com

Department of Orthodontics and Dentofacial Orthopaedics, Maulana Azad Institute of Dental Sciences, Bahadur Shah Zafar Marg, New Delhi 110002, India
}

(c) The Author(s). 2021 Open Access This article is licensed under a Creative Commons Attribution 4.0 International License which permits use, sharing, adaptation, distribution and reproduction in any medium or format, as long as you give appropriate credit to the original author(s) and the source, provide a link to the Creative Commons licence, and indicate if changes were made. The images or other third party material in this article are included in the article's Creative Commons licence, unless indicated otherwise in a credit line to the material. If material is not included in the article's Creative Commons licence and your intended use is not permitted by statutory regulation or exceeds the permitted use, you will need to obtain permission directly from the copyright holder. To view a copy of this licence, visit http://creativecommons.org/licenses/by/4.0/.

Numerous methods have been developed to assess the developmental status, among which skeletal maturity is most widely used. This could be assessed through several biological indicators like height [1-3], weight [4], chronological age $[5,6]$, skeletal maturation of handwrist [7-9], and changes in the morphology of cervical vertebrae [10-14].

Hand-wrist radiographic method, initially developed by Todd [15] and followed by various authors [16, 17], is a well-established method for assessing skeletal maturation. It is based on various morphological changes and 
ossification events occurring in the carpal bones. In spite of its accuracy, the major drawback resides in the requirement of an additional radiograph. Lateral cephalogram radiograph is a routine orthodontic investigation. Assessment of skeletal maturation through cervical vertebral maturation index (CVMI) was a technique described by Lamparski [12] in 1972 and later modified by Baccetti et al. [10].

CVMI, albeit widely used, suffers from low reproducibility, subjective perception of the practitioner [18, 19], issue in staging cephalometric radiographs with radiographic noise, complexity in the identification of landmarks, and borderline subjects [20]. Further, it has been established that the cervical column differs in numerous skeletal jaw relationships and pressure; morphology of facial components and body posture alter the height of vertebral bodies and thus have an effect on the reliability of CVMI.

Newer possibilities are provided with biochemical markers that are involved in bone growth and remodeling [21, 22]. An increase in their levels is correlated to the peak circumpubertal growth [22]. These biomarkers can be procured from various biological fluids such as blood, saliva, gingival crevicular fluid (GCF), and urine. They permit the possibility of quantification, overcoming the subjective errors associated with the radiographs.

Saliva, GCF, and urine have the advantage of avoiding invasive blood collection. It is additionally useful in clinically challenging situations such as obtaining samples from children or anxious patients where blood sampling might be a difficult act to perform. The primary goal of the present article was to identify and summarize the biomarkers assessed through non-invasive methods and their correlation with radiographic maturity indicators.

\section{Methodology}

The literature search was carried out in MEDLINE via Pubmed, Cochrane Library (Cochrane database of systematic reviews), Cochrane central register of controlled trials (CENTRAL), Google Scholar, Semantic Scholar, ScienceDirect, and Opengrey.eu for articles up to and including November 2020. The keywords used were saliva, GCF, Gingival Crevicular fluid, urine, biomarker, marker, pubert*, matur", cervical vertebra", radiograph", hand-wrist, skeletal age. The titles and abstracts of the articles found were read to match the inclusion criteria. The inclusion criteria were (a) human studies that used non-invasive methods for assessing biomarker, (b) studies assessing skeletal maturity/pubertal growth spurt, and (c) studies using cervical vertebral maturation index or hand-wrist methods as their radiographic indicator. The exclusion criteria were (a) studies that collected serum samples, (b) animal studies, (c) reviews, (d) studies conducted on subjects with systemic conditions, and (e) articles in languages other than English. The search resulted in 682 articles. Removal of duplicates and the articles pertinent to the inclusion and exclusion criteria were evaluated.

\section{Results}

A total of 682 articles, following the database search, were reviewed. The redundant articles were removed. Twelve articles were selected for full-text review and summarized based on the following information: biomarker assessed, sample size and characteristics, sample collection protocol, processing of sample, biomarker detection method, and the radiographic method used (Table 1). All 12 studies were cross-sectional and included subjects of both the genders except two studies $[28,34]$ that only had female participants. The age group in the studies ranged from 6 to 24 years. The noninvasive methods used were saliva [23-30], GCF [3133], and urine [34].

\section{Saliva}

Out of the 12 articles, 8 studies [23-29] employed saliva as their sample. The biomarkers assessed in the eight studies were insulin-like growth factor 1 (IGF1) [23, 29], alkaline phosphatase (ALP) [26, 27, 34], bone-specific alkaline phosphatase (B-ALP) [24, 25], vascular endothelial growth factor (VEGF) [29], and dehydroepiandrosterone (DHEA) [30].

Hegde et al. [25] and Tarvade et al. [27] used handwrist radiographic method for correlation, while the remaining six studies used CVMI as their radiographic indicator.

Nayak et al. [23] found IGF1 levels to increase during the period of accelerated velocity (QCVM II).

Salivary ALP levels were assessed in three studies. Irham et al. [28] found a significant increase in ALP levels during pubertal phase. The study by Tarvade et al. [27] that used middle phalanx of the third finger (MP3) staging to correlate found the ALP levels to increase during G stage of MP3. However, Alhazmi et al. [26] concluded that the ALP levels were higher only during the CVM stage 1.

The study by Wijaya et al. [24] which assessed the BALP levels did not find any significant difference across the various CVMI groups. On the contrary, Hegde et al. [25] concluded the BALP levels to increase during the peak pubertal phase (MP3-G stage).

VEGF and IGF assessed by Sharmila et al. [29] did not find any significant difference in VEGF levels across the various CVMI stages but found the IGF1 levels to increase during the pubertal growth phase.

A gradual increase in DHEA levels from CVMI stage 1 to stage 6 was found by Sangeeth et al. [30] with the highest levels during stages 5 and 6 . 


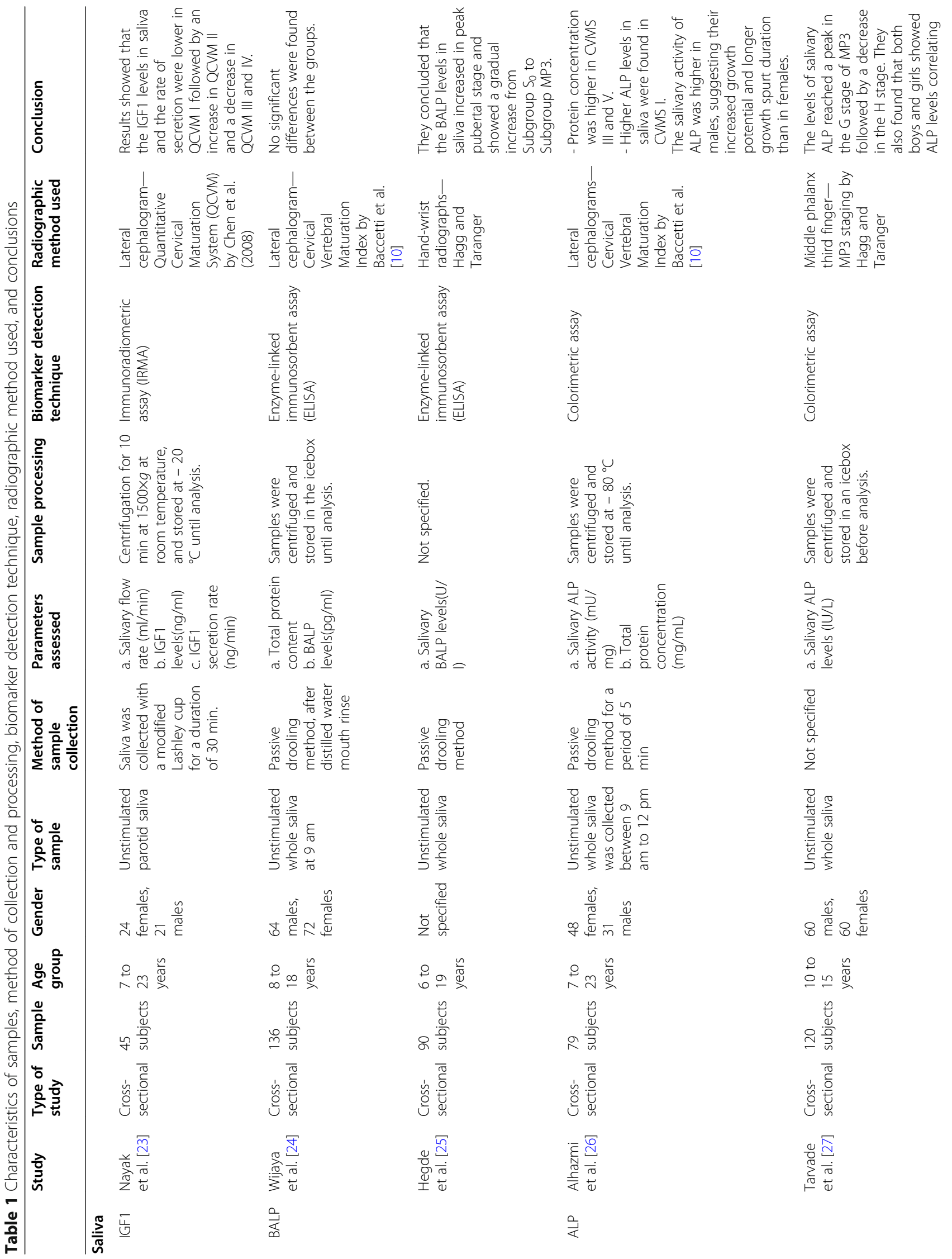




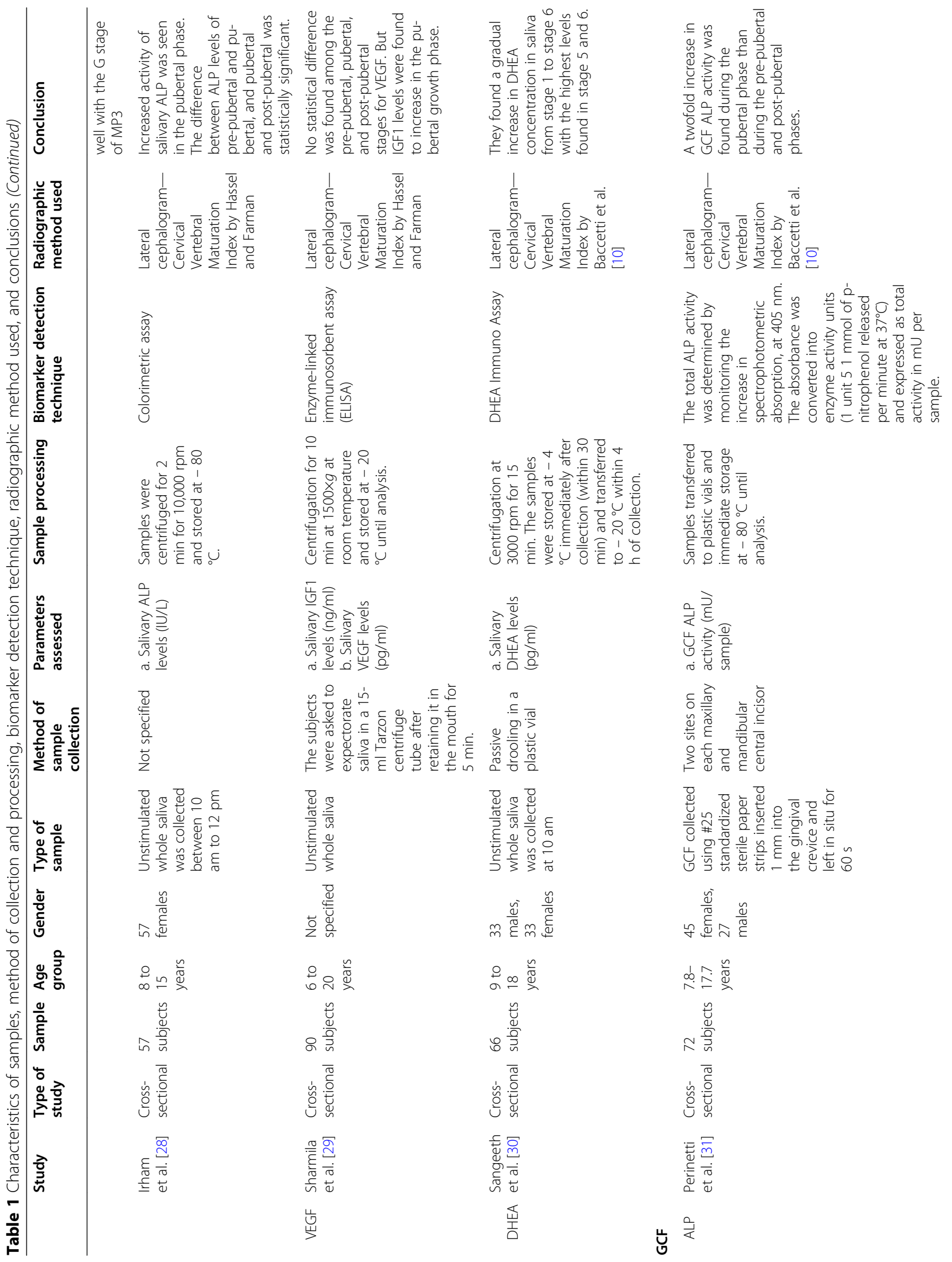




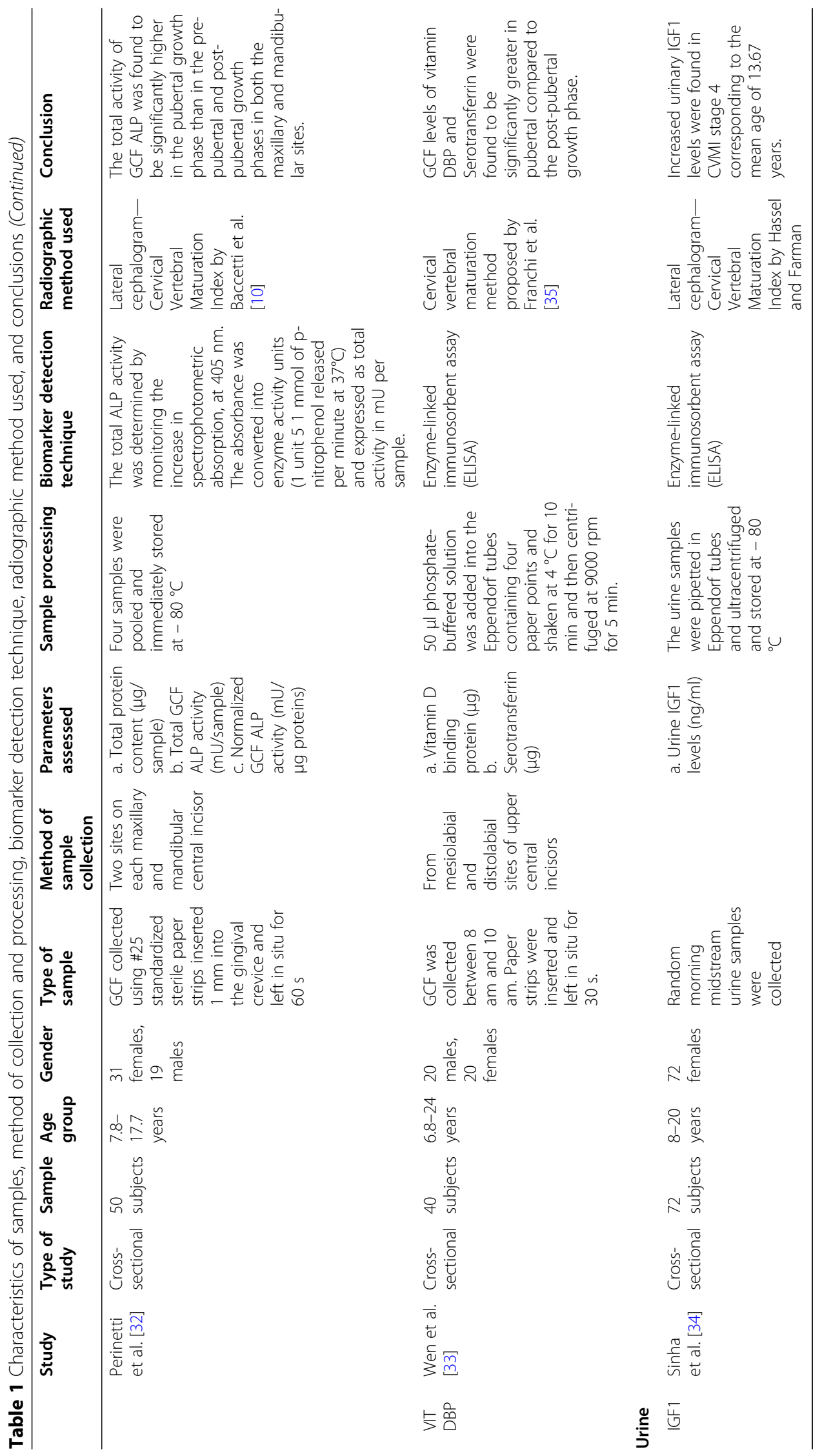




\section{GCF}

Three studies [31-33] collected GCF. Perinetti et al. [31, 32] correlated the GCF ALP activity using CVMI. They found a twofold increase in GCF ALP levels during the pubertal phase. Wen et al. [33] found the levels of vitamin D binding protein (VIT DBP) and serotransferrin (Tf) to increase during pubertal growth phase (CVM 3 and 4) compared to the other proteins detected.

\section{Urine}

Only one study collected urine [34]. The biomarker assessed was IGF1 using CVMI radiographic indicator. The study was conducted only in female subjects. They found an increase in IGF1 levels during CVMI stage 4.

\section{Discussion}

The well-known intra-individual variations in the concentration of biomarkers throughout the various anabolic and catabolic processes preclude their use for diagnostic purposes. Saliva, GCF, and urine hold the benefit of being non-invasive methods.

\section{Saliva}

Out of the twelve studies reviewed in this article, 8 studies collected saliva samples. It was noticed that every study adopted its own protocol of procedures for sample collection such as time of collection, refraining from eating and drinking, before or after tooth brushing, and oral hygiene. Most of the studies instructed the patients to refrain from eating and drinking 30 to $90 \mathrm{~min}$ before collection. In all the studies, there is a strong consensus in the collection of unstimulated saliva. In salivary diagnostics, though it is well documented that there is an increase in the salivary flow following stimulation [36], it contains only a diluted concentration of biomarkers that might be tough to detect [37]. Hence, unstimulated saliva is usually preferred. However, unstimulated saliva is affected by factors like the degree of hydration, position of the head during collection, drugs, and circadian rhythm. Stimulation of parotid salivary flow with 5\% citric led to a decrease in the concentration of IGF1 considerably [38].

In terms of the site of sample collection, all studies collected the whole saliva except Nayak et al. [23] that collected parotid saliva. Literature suggests collecting whole saliva is an easier and feasible method [39].

Six out of 8 studies collected saliva by a passive drooling method. Nayak et al. [23] collected saliva with a modified Lashley cup over the parotid gland and Sharmila et al. [29] by saliva accumulation for $5 \mathrm{~min}$ and then expectorating it. In the spitting method, 14 times more bacteria were present in samples compared to the drooling method. This could affect the storage and analysis of proteins [40].

\section{Gingival crevicular fluid}

The constituents of gingival crevicular fluid include host-derived enzymes, plasma and serum components, inflammatory cells, and immune cells. In healthy state, the protein concentration in GCF is found to be similar to the interstitial fluid [41]. All the three studies collected GCF by absorbent paper strip technique as this method is quick and easy and also because of the ability of the strips to quickly absorb the fluid [41]. In two studies, samples were taken from two sites of maxillary and mandibular central incisors, whereas in one study samples were taken from the mesiolabial and distolabial aspect of only maxillary central incisors.

\section{Urine}

Though urine can be collected in large volumes repeatedly, limited literature is available on its use for detecting biomarkers related to skeletal maturity. Urine proteomics differ depending upon factors like age, gender, diet, hormonal status, and circadian rhythm [42]. Study conducted by Sinha et al. [34] collected random morning midstream urine sample only in female subjects.

\section{Circadian flow}

The time of sample collection will vary the result greatly due to the effect of the circadian rhythm on the protein concentrations [43]. IGF1 demonstrates little diurnal variations with levels peaking slightly during morning hours [38]. The B-ALP is the only marker not influenced by circadian rhythm due to its molecular structure [44]. DHEA showed considerable diurnal variation with higher hormonal levels in the morning than later in the day. Among the 12 studies, 6 collected samples in the morning.

Among the 12 articles reviewed, 3 studies employed IGF1 as their biomarker out of which two studies were conducted in saliva and one in urine. The quantification of growth hormone $(\mathrm{GH})$ becomes intricate due to its strong binding capacity to $\mathrm{GH}$ binding protein, providing unreliable information about the functionally active $\mathrm{GH}$. The continuous diurnal variation also abuts to its difficulty in estimation. Longitudinal studies have enunciated the direct modulating effects of IGF1 on GH [45]. It has an influence on bone growth and formation, showing variations periodically during bone growth. Nayak et al. [23] measured the levels of IGF1 in saliva and correlated it with the quantitative cervical vertebral maturation index. They concluded that the levels increased during the period of accelerated velocity. Similarly, the results of Sharmila et al. [29] showed the levels of salivary IGF1 to reach a peak during the pubertal stage. This was in agreement with previous studies which correlated the serum IGF and found peak levels 
during pubertal growth [34, 46-52]. Few studies also found a disparity in IGF1 levels in males and females across the CVMI stages as IGF1 levels are influenced by sex [53]. Sinha et al. [34] conducted the study only on female subjects to avoid gender bias and noted the urinary IGF1 levels to increase during CVMI stage 4, corresponding to the mean age of 13.67 years. Since these studies have emphasized that the salivary and urine IGF1 levels follow a similar pattern of secretion rate to serum IGF, they can be used as an indicator of residual mandibular growth.

Alkaline phosphatase activity was correlated in 5 [26$28,31,32]$ out of 12 studies. Salivary ALP activity was measured in three studies. Alkaline phosphatase catalyzes the hydrolysis of phosphate ester groups and helps in hydroxyapatite crystallization. It is widely used as a biomarker for pathological states of liver and bone. Irham et al. [28] and Alhazmi et al. [26] compared it with CVMI staging while Travade et al. [27] used the Hagg and Taranger method (ossification of middle phalanx of the third finger-MP3) as their radiographic indicator. This method evaluates skeletal maturity based on the capping of epiphysis of the middle phalanx of the third finger. They are divided into five stages: MP3 F, MP3 FG, MP3 G, MP3 H, and MP3 I. MP3FG stage indicates acceleration towards pubertal peak; $G$ stage indicates the peak pubertal phase followed by a deceleration $\mathrm{H}$ stage. Alhazmi et al. [26] noted the salivary ALP levels to be higher in CVMI 1 and males. They suggested that this could be due to the increased growth potential and long growth spurt duration in males than in females. They also found that the total protein concentration was higher in CVMI 3 and 5. Irham et al. [28] conducted the study only on female subjects and found the ALP levels to rise during the pubertal phase. The levels in the study by Travade et al. [27] showed a peak in the G stage of MP3.

Two studies [31, 32] determined the levels of ALP in GCF and correlated it with CVMI stages. Perinetti et al. [31] found a twofold increase in levels during the pubertal growth phase. The other study [32] found an increase in total enzyme activity (mU/sample) during $\mathrm{C} 3$ and $\mathrm{C} 4$ stages. No significant difference was found on correlat-

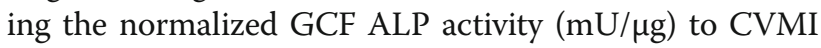
stages, thus eliminating it as an indicator for skeletal maturation.

Bone-specific ALP (B-ALP), an isozyme of ALP, is an important product of osteoblasts involved in the process of bone mineralization [44]. It is a more sensitive marker that becomes readily detectable even with minor fluctuations. BALP levels were assessed by Hegde et al. [25] and Wijaya et al. [24] in saliva. Hedge et al. [25] concluded that the levels increased in peak pubertal stage and showed a gradual increase from subgroup $S_{0}$ to
$\mathrm{MP}_{3}$. The results were consistent with the studies which correlated serum BALP levels with CVMI in males and females [49]. Serum BALP correlated with Tanner's pubertal stages and chronologic age also revealed similar results $[44,54,55]$. However, the study by Wijaya et al. [24] revealed results on the contrary showing no significant differences between pre-pubertal and pubertal groups.

The vascular endothelial growth factor is a potent angiogenic and an essential growth factor of vascular endothelial cells [56]. Zelzer et al. first described the connection between VEGF and chondrocytes during skeletal development [57]. An in vitro study on human osteoblast cells suggested that VEGF promotes osteoblasts and alkaline phosphatase activity. The possible non-vascular activities of VEGF in bone ossification have led to a presumption that it might have a role in skeletal maturity.

Nevertheless, the study by Sharmila et al. [29] found no significant difference in salivary VEGF levels among the pre-pubertal, pubertal, and post-pubertal stages, and the levels were found to decrease with pubertal and post-pubertal stages. Further studies need to be carried out to substantiate it as a biomarker for assessing skeletal maturity.

Dehydroepiandrosterone (DHEA) is an intermediate during the synthesis of androgen and estrogen [58]. They improve bone mineral density. Studies have emphasized that the first peak in DHEA levels occur between 6 and 7 years of age, the second peak during puberty, and gradually increases till it reaches adult values [59-61].

Sangeeth et al. [30] found that the DHEA levels in saliva increased from stage 1 to stage 6 . Similar results were obtained with the study conducted by Netherton et al. [62] and Matchock et al. [63] that correlated the levels with Tanner's pubertal growth stages. Srinivasan et al. [64] correlated the serum levels of DHEA with hand-wrist methods and found an increase during the pubertal growth phase.

The study conducted by Wen et al. [33] detected a total of 537 proteins in GCF among which the levels of vitamin $\mathrm{D}$ binding protein and serotransferrin were found to be significantly higher during the pubertal growth phase. An increase in serum levels of transferrin in boys during puberty was reported by Antilla et al. [65]. No other studies in the literature have correlated vitamin DBP to skeletal maturity.

\section{Scope for future research}

It is critical to harness the full growth potential of an individual to reduce the burden of surgical intervention at a later stage. Using saliva, GCF, and urine for assessing skeletal maturity is practical, non-invasive, and 
repeatable. Despite its advantages, the studies cited above assessing the same biomarker through same biologic fluid had deviations in the sample collection method, time of collection, processing, and storage temperature. All these could affect the reproducibility and sensitivity of non-invasive methods. Furthermore, longitudinal studies with standardization of protocol would be expedient to conclude any biomarker as a skeletal maturity indicator.

Studies indicate that growth factors like VEGF and IGF-1 play a major role in the proliferative activity of condylar cartilage in skeletal class III malocclusion. Translational research identifying the protein expression in different malocclusions will provide a rationale for diagnosis in orthodontics and dentofacial orthopedics.

Till date, one of the major challenges is the development of a robust, versatile, and sensitive clinical tool for chairside practice which would warrant the use of noninvasive methods for assessing skeletal maturity.

\section{Conclusion}

Considerable literature on the diagnostic possibilities of saliva, GCF, urine, and their implications in orthodontics and dentofacial orthopedics is available. Unlike radiographs, assessing skeletal maturity through non-invasive methods can be repeated at much shorter intervals and the biomarkers can be quantified. There is adequate agreement among the available studies that the level of certain biomarkers peak during the pubertal growth phase (i.e., C3 and C4 of CVMI and G stage of MP3). However, significant drawbacks of saliva collection are variation in the method, processing, and storage temperature which may affect the biomarker levels. GCF is technique sensitive and contamination with blood and saliva can occur during collection. Also, different biomarkers require different assay. If effort is taken to mitigate all the abovementioned issues, the heterogeneity can be minimized, and clinical effectiveness can be greatly improved. The scope is vast but the standardization of procedures still remains to be further investigated.

\footnotetext{
Abbreviations

CVMI: Cervical Vertebral Maturation Index; GCF: Gingival crevicular fluid; IGF1: Insulin-like growth factor 1; ALP: Alkaline phosphatase; B-ALP: Bonespecific alkaline phosphatase; VEGF: Vascular endothelial growth factor; DHEA: Dehydroepiandrosterone; VIT DBP: Vitamin D binding protein; Tf: Serotransferrin; QCVM: Quantitative Cervical Vertebral Maturation Index; GH: Growth hormone; MP3: Middle phalanx of the third finger; ELISA: Enzyme-Linked Immunosorbent Assay; IRMA: Immunoradiometric assay
}

\section{Authors' contributions}

$\pi$ conceptualized the idea of the current review and supervised the study. GV was responsible for compiling all the data and formulating the manuscript. The authors read and approved the final manuscript.

\section{Funding}

The study is self-funded.

Availability of data and materials

Not applicable

\section{Declarations}

Ethics approval and consent to participate

Not applicable

Consent for publication

Not applicable

\section{Competing interests}

The authors declare that they have no competing interests.

Received: 15 January 2021 Accepted: 1 July 2021

Published online: 06 September 2021

References

1. Pancherz $\mathrm{H}$, Hägg U. Dentofacial orthopedics in relation to somatic maturation. An analysis of 70 consecutive cases treated with the Herbst appliance. Am J Orthod. 1985;88(4):273-87. https://doi.org/10.1016/0002-941 6(85)90126-5.

2. Björk A, Helm S. Prediction of the age of maximum puberal growth in body height. Angle Orthod. 1967;37(2):134-43. https://doi.org/10.1043/0003-321 9(1967)037<0134:POTAOM>2.0.CO;2.

3. Hunter CJ. The correlation of facial growth with body height and skeletal maturation at adolescence. Angle Orthod. 1966;36(1):44-54. https://doi. org/10.1043/0003-3219(1966)036<0044:TCOFGW>2.0.CO;2.

4. Green $L$ J. The interrelationships among height, weight and chronological, dental and skeletal ages. Angle Orthod. 1961 Jul 1;31(3):189-93.

5. Fishman LS. Chronological versus skeletal age, an evaluation of craniofacial growth. Angle Orthod. 1979;49(3):181-9. https://doi.org/10.1043/0003-321 9(1979)049<0181:CVSAAE>2.0.CO;2.

6. Hägg U, Taranger J. Maturation indicators and the pubertal growth spurt. Am J Orthod. 1982;82(4):299-309. https://doi.org/10.1016/0002-9416(82)904 64-X.

7. Flores-Mir C, Nebbe B, Major PW. Use of skeletal maturation based on handwrist radiographic analysis as a predictor of facial growth: a systematic review. Angle Orthod. 2004;74(1):118-24.

8. Hägg U, Taranger J. Skeletal stages of the hand and wrist as indicators of the pubertal growth spurt. Acta Odontologica Scand. 1980;38(3):187-200. https://doi.org/10.3109/00016358009004719.

9. LS F. Radiographic evaluation of skeletal maturation. A clinically oriented method based on hand-wrist films. Angle Orthod. 1982;52(2):88-112.

10. Baccetti T, Franchi L, McNamara JA. The cervical vertebral maturation (CVM) method for the assessment of optimal treatment timing in dentofacial orthopedics. Seminars Orthod. 2005;11(3):119-29. https://doi.org/10.1053/j. sodo.2005.04.005

11. Baccetti T, Franchi L, McNamara JA. An improved version of the cervical vertebral maturation (CVM) method for the assessment of mandibular growth. Angle Orthod. 2002;72(4):316-23. https://doi.org/10.1043/0003-321 9(2002)072<0316:AIVOTC>2.0.CO;2.

12. Lamparski DG. Skeletal age assessment utilizing cervical vertebrae. Master of Science Thesis, University of Pittsburg; 1972.

13. Hassel B, Farman AG. Skeletal maturation evaluation using cervical vertebrae. Am J Orthod Dentofacial Orthop. 1995;107(1):58-66. https://doi. org/10.1016/S0889-5406(95)70157-5.

14. Chen L, Lin J, Xu T, Long X. The longitudinal sagittal growth changes of maxilla and mandible according to quantitative cervical vertebral maturation. J Huazhong Univ Sci Technol. 2009;29(2):251-6. https://doi.org/1 0.1007/s11596-009-0224-z

15. Todd TW. Atlas of Skeletal Maturation. Part 1, Hand. London: Kimpton; 1937. 
16. Tanner JM, Whitehouse RH. Atlas of children's growth: normal variation and growth disorders. London: Academic Press; 1982

17. Greulich WW, Pyle SI. Radiographic atlas of skeletal development of the hand and wrist: Based on the Brush Foundation study of human growth and development initiated by T. Wingate Todd, MB, Ch. B., FRCS. Stanford University Press; 1950.

18. Zhao X-G, Lin J, Jiang J-H, Wang Q, Ng SH. Validity and reliability of a method for assessment of cervical vertebral maturation. Angle Orthod. 2012;82(2):229-34. https://doi.org/10.2319/051511-333.1.

19. Perinetti $\mathrm{G}$, Contardo L. Reliability of growth indicators and efficiency of functional treatment for skeletal class II malocclusion: current evidence and controversies. BioMed Res Int. 2017;2017:1-19. https://doi.org/10.1155/201 7/1367691.

20. Nestman TS, Marshall SD, Qian F, Holton N, Franciscus RG, Southard TE. Cervical vertebrae maturation method morphologic criteria: poor reproducibility. Am J Orthod Dentofacial Orthop. 2011;140(2):182-8. https:// doi.org/10.1016/j.ajodo.2011.04.013.

21. Cepelak I, Cvoriscec D. Biochemical markers of bone remodeling - review. Biochem Med. 2009:17-35. https://doi.org/10.11613/BM.2009.003.

22. de Ridder CM, Delemarre-van de Waal HA. Clinical utility of markers of bone turnover in children and adolescents. Curr Opin Pediatr. 1998;10(4):441-8. https://doi.org/10.1097/00008480-199808000-00020.

23. Nayak S, Bhad (Patil) WA, Doshi UH. The relationship between salivary insulin-like growth factor I and quantitative cervical maturational stages of skeletal maturity. J Orthod. 2014;41(3):170-174, DOI: https://doi.org/10.11 79/1465313313Y.0000000091.

24. Wijaya H, Kusdhany LS, Redjeki S, Soegiharto BM. The salivary bone spesific alkaline phosphatase in relation to pubertal growth phase in Indonesian children. Asian J Pharm Clin Res. 2017;10(5):389. https://doi.org/10.22159/a jpcr.2017.v10i5.17752.

25. Hegde S, Revankar A, Patil A. Identification of bone-specific alkaline phosphatase in saliva and its correlation with skeletal age. Indian J Dent Res. 2018;29(6):721-5. https://doi.org/10.4103/ijdr.IJDR_298_15.

26. Alhazmi N, Trotman CA, Finkelman M, Hawley D, Zoukhri D, Papathanasiou E. Salivary alkaline phosphatase activity and chronological age as indicators for skeletal maturity. Angle Orthod. 2019;89(4):637-42. https://doi.org/10.231 9/030918-197.1.

27. Tarvade, et al. Salivary alkaline phosphatase- a biochemical marker for growth prediction. Indian J Basic Appl Med Res. 2015;4(3):17-22.

28. Irham F, Bahirrah S, Nazruddin D. The level of alkaline phosphatase in saliva as biomarker for pubertal growth phase. In: Proceedings of the International Dental Conference of Sumatera Utara 2017. Medan: Atlantis Press; 2018.

29. Sharmila et al. IGF-1 and VEGF in saliva and its relation with CVMI stages in determining the skeletal maturity, 2017. http://repositorytnmgrmuac.in/id/ eprint/5271.

30. K. Sangeeth. Evaluation and comparison of salivary dehydroepiandrosterone (DHEA) levels and cervical vertebral maturation stages at pre-pubertal, pubertal and post-pubertal stages of growth, 2017. http://repositorytnmgrmu.ac.in/5276

31. Perinetti G, Baccetti T, Contardo L, Di Lenarda R. Gingival crevicular fluid alkaline phosphatase activity as a non-invasive biomarker of skeletal maturation: GCF ALP activity and skeletal maturation. Orthod Craniofacial Res. 2011;14(1):44-50. https://doi.org/10.1111/j.1601-6343.2010.01506.x.

32. Perinetti G, Franchi L, Castaldo A, Contardo L. Gingival crevicular fluid protein content and alkaline phosphatase activity in relation to pubertal growth phase. The Angle Orthodontist. 2012;82(6):1047-52. https://doi.org/1 0.2319/123111-806.1.

33. Wen $X$, Franchi $L$, Chen F, Gu Y. Proteomic analysis of gingival crevicular fluid for novel biomarkers of pubertal growth peak. Eur J Orthod. 2018;40(4): 414-22. https://doi.org/10.1093/ejo/cjx082.

34. Sinha M, Tripathi T, Rai P, Gupta SK. Serum and urine insulin-like growth factor-1 as biochemical growth maturity indicators. Am J Orthod Dentofacial Orthop. 2016;150(6):1020-7. https://doi.org/10.1016/j.ajodo.2016.04.028

35. Franchi L, Baccetti T, McNamara JA Jr. Mandibular growth as related to cervical vertebral maturation and body height. Am J Orthod Dentofacial Orthop. 2000;118(3):335-40.

36. Benedek-Spät E. The composition of stimulated human parotid saliva. Archives of Oral Biology. 1973;18(9):1091-7. https://doi.org/10.1016/00039969(73)90082-4

37. Malamud D. Saliva as a diagnostic fluid. Dental Clinics of North America. 2011;55(1):159-78. https://doi.org/10.1016/j.cden.2010.08.004.
38. Ryan J, Mantle T, Costigan DC. A normal population study of human salivary insulin-like growth factor 1 (IGF 1) concentrations from birth through puberty. J Clin Endocrinol Metab. 1992;74(4):774-8. https://doi.org/10.1210/ jcem.74.4.1548339.

39. Priya Y, Prathibha M. Methods of collection of saliva-a review. 2017 [cited 2020 Aug 30]. http://oaji.net/articles/2017/1994-1508144687.pdf

40. Pathiyil V, Udayasankar R. Salivary diagnostics. In: Gokul S, editor. Saliva and Salivary Diagnostics IntechOpen; 2019.

41. Papagerakis $P$, Zheng $L$, Kim D, Said R, Ehlert AA, Chung KKM, et al. Saliva and gingival crevicular fluid (GCF) collection for biomarker screening. In: Papagerakis P, editor. Odontogenesis. New York: Springer New York; 2019. p. 549-62. [cited 2020 Dec 20] (Methods in Molecular Biology; vol. 1922). http://link.springer.com/10.1007/978-1-4939-9012-2_41.

42. Harpole M, Davis J, Espina V. Current state of the art for enhancing urine biomarker discovery. Expert Review of Proteomics. 2016;13(6):609-26. https://doi.org/10.1080/14789450.2016.1190651.

43. Humphrey SP, Williamson RT. A review of saliva: Normal composition, flow, and function. The Journal of Prosthetic Dentistry. 2001;85(2):162-9. https:// doi.org/10.1067/mpr.2001.113778.

44. Tobiume H, Kanzaki S, Hida S, Ono T, Moriwake T, Yamauchi S, et al. Serum bone alkaline phosphatase isoenzyme levels in normal children and children with growth hormone $(\mathrm{GH})$ deficiency: a potential marker for bone formation and response to GH therapy. J Clin Endocrinol Metab. 1997;82(7): 2056-61. https://doi.org/10.1210/jcem.82.7.4081

45. Nilsson A, Isgaard J, Lindahl A, Dahlström A, Skottner A, Isaksson OG. Regulation by growth hormone of number of chondrocytes containing IGFI in rat growth plate. Science. 1986 Aug 1;233(4763):571-4. https://doi.org/1 $0.1126 /$ science. 3523759 .

46. Gupta S, Jain S, Gupta P, Deoskar A. Determining skeletal maturation using insulin-like growth factor I (IGF-I) test. Progress in Orthodontics. 2012;13(3): 288-95. https://doi.org/10.1016/j.pio.2011.09.006

47. Jain N, Tripathi T, Gupta SK, Rai P, Kanase A, Kalra S. Serum IGF-1, IGFBP-3 and their ratio: potential biochemical growth maturity indicators. Prog Orthod. 2017:18(1):11. https://doi.org/10.1186/s40510-017-0165-1.

48. Tripathi T, Gupta P, Rai P, Sharma J, Gupta VK, Singh N. Osteocalcin and serum insulin-like growth factor-1 as biochemical skeletal maturity indicators. Prog Orthod. 2017;18(1):30. https://doi.org/10.1186/s40510-017-0184-y.

49. Tripathi T, Gupta P, Sharma J, Rai P, Gupta VK, Singh N. Bone-specific alkaline phosphatase - a potential biomarker for skeletal growth assessment. J Orthod. 2018;45(1):4-10. https://doi.org/10.1080/14653125.201 7.1416571.

50. Masoud M, Masoud I, Kent RL, Gowharji N, Cohen LE. Assessing skeletal maturity by using blood spot insulin-like growth factor I (IGF-I) testing. Am J Orthod Dentofacial Orthop. 2008;134(2):209-16. https://doi.org/10.1016/j.a jodo.2006.09.063.

51. Nancy ED, Yezdani AA, Kannan MS, Kumar SK, Padmavathy K. Serum insulin like growth factor-1- a skeletal maturity indicator for the assessment of orthopedic treatment timing of skeletal class II malocclusion. Biomed Pharmacol J. 2019:12(1):233-8. https://doi.org/10.13005/bpj/1632.

52. Ishaq RAR, Soliman SAZ, Foda MY, Fayed MMS. Insulin-like growth factor I: a biologic maturation indicator. Am J Orthod Dentofacial Orthop. 2012;142(5): 654-61. https://doi.org/10.1016/j.ajodo.2012.06.015.

53. Juul A, Bang P, Hertel NT, Main K, Dalgaard P, Jørgensen K, Müller J, Hall K, Skakkebaek NE. Serum insulin-like growth factor-I in 1030 healthy children, adolescents, and adults: relation to age, sex, stage of puberty, testicular size, and body mass index. J Clin Endocrinol Metab. 1994;78(3):744-52.

54. Mora S, Pitukcheewanont P, Kaufman FR, Nelson JC, Gilsanz V. Biochemical markers of bone turnover and the volume and the density of bone in children at different stages of sexual development. J Bone Miner Res. 1999; 14(10):1664-71. https://doi.org/10.1359/jbmr.1999.14.10.1664.

55. Tsai K-S, Jang M-H, Hsu SH-J, Cheng W-C, Chang M-H. Bone alkaline phosphatase isoenzyme and carboxy-terminal propeptide of type-I procollagen in healthy Chinese girls and boys. Clin Chem. 1999;45(1):136-8. https://doi.org/10.1093/clinchem/45.1.136.

56. Maes C, Carmeliet G. Vascular and nonvascular roles of VEGF in bone development. In: Ruhrberg C, editor. VEGF in development. New York: Springer; 2008. p. 79-90. [cited 2020 Aug 23] (Molecular Biology Intelligence Unit). https://doi.org/10.1007/978-0-387-78632-2 7 .

57. Zelzer E, Mamluk R, Ferrara N, Johnson RS, Schipani E, Olsen BR. VEGFA is necessary for chondrocyte survival during bone development. Development. 2004;131(9):2161-71. https://doi.org/10.1242/dev.01053. 
58. von Mühlen D, Laughlin GA, Kritz-Silverstein D, Bergstrom J, Bettencourt R. Effect of dehydroepiandrosterone supplementation on bone mineral density, bone markers, and body composition in older adults. Osteoporos Int. 2008;19(5):699-707. https://doi.org/10.1007/s00198-007-0520-z.

59. Hopper BR, Yen SSC. Circulating concentrations of dehydroepiandrosterone and dehydroepiandrosterone sulfate during puberty. J Clin Endocrinol Metab. 1975;40(3):458-61. https://doi.org/10.1210/jcem-40-3-458.

60. Sulcová J, Hill M, Hampl R, Stárka L. Age and sex related differences in serum levels of unconjugated dehydroepiandrosterone and its sulphate in normal subjects. J Endocrinol. 1997;154(1):57-62. https://doi.org/10.1677/joe. 0.1540057 .

61. Kulik-Rechberger B, Furmaga-Jabłońska W, Rechberger T. The role of dehydroepiandrosterone sulfate during puberty in girls. Ginekol Pol. 2000; 71(8):668-72.

62. Netherton C, Goodyer I, Tamplin A, Herbert J. Salivary cortisol and dehydroepiandrosterone in relation to puberty and gender. Psychoneuroendocrinology. 2004;29(2):125-40. https://doi.org/10.1016/S03 06-4530(02)00150-6

63. Matchock RL, Dorn LD, Susman EJ. Diurnal and seasonal cortisol, testosterone, and DHEA rhythms in boys and girls during puberty. Chronobiol Int. 2007;24(5):969-90. https://doi.org/10.1080/07420520701649471.

64. Srinivasan B, Premkumar S. Assessment of serum dehydroepiandrosterone sulphate in subjects during the pre-pubertal, pubertal, and adult stages of skeletal maturation. The European Journal of Orthodontics. 2012 Aug 1; 34(4):447-51. https://doi.org/10.1093/ejo/cjr041.

65. Anttila $R$, Siimes MA. Serum transferrin and ferritin in pubertal boys: relations to body growth, pubertal stage, erythropoiesis, and iron deficiency. Am J Clin Nutr. 1996;63(2):179-83. https://doi.org/10.1093/ajcn/63.2.179.

\section{Publisher's Note}

Springer Nature remains neutral with regard to jurisdictional claims in published maps and institutional affiliations.

\section{Submit your manuscript to a SpringerOpen ${ }^{\circ}$ journal and benefit from:}

- Convenient online submission

- Rigorous peer review

- Open access: articles freely available online

High visibility within the field

- Retaining the copyright to your article

Submit your next manuscript at $\boldsymbol{\nabla}$ springeropen.com 